Abstract

\title{
Sustainable Multi-Target Drugs for Neglected Tropical Diseases Caused by Trypanosomatids: Dream or Reality? ${ }^{+}$
}

\author{
Maria Laura Bolognesi \\ Department of Pharmacy and Biotechnology, Alma Mater Studiorum-University of Bologna, \\ 40126 Bologna BO, Italy; marialaura.bolognesi@unibo.it \\ † Presented at the 1st Molecules Medicinal Chemistry Symposium, Barcelona, Spain, 8 September 2017.
}

Published: 26 October 2017

The development of nifurtimox-eflornithine combination therapy (NECT) has been a major and emboldening advance towards more effective and simple medications in the field of neglected tropical diseases (NTD) caused by Trypanosomatids. In this context, novel prospects for curing such diseases are offered by the strategy of developing single chemical entities able to modulate multiple targets simultaneously, namely the multi-target-directed ligands (MTDLs) [1]. Similarly to that observed in the anti-cancer field, we argue that NTD therapy might also benefit from the potential of reduced resistance, improved efficacy, and reduction of dosage and treatment length. Thus, the MTDLs could offer a simpler and more cost-effective treatment [1]. In this context, we have reported on the hit compound 2-phenoxy-1,4-naphthoquinone (B6), with a remarkable activity against Trypanosoma brucei rhodesiense in a phenotypic assay $(\mathrm{IC} 50=80 \mathrm{nM})$ and a promising selectivity index [2]. Particularly, B6 showed a multitarget mechanism of action, including radical production and covalent inhibition of Trypanosoma brucei glyceraldehyde 3-phosphate dehydrogenase (TbGAPDH) enzyme [3].

As a further step, we recently explored the possibility to discover new MTDLs based on inexpensive resources. Particularly, we were attracted by the opportunity of using food waste products as sustainable starting materials. Towards this aim, we have developed a series of novel MTDLs obtained by combining the 2-phenoxy-1,4-naphthoquinone scaffold with those of phenolic constituents from the cashew nut shell liquid (CNSL), which is an agro waste from cashew nut processing factories.

We envisage that such hybrid compounds, obtained from renewable and inexpensive material, might be promising bio-based, sustainable MTDLs for antitrypanosomatid drug discovery.

Conflicts of Interest: The authors declare no conflict of interest.

\section{References}

1. Cavalli, A.; Bolognesi, M.L. Neglected tropical diseases: Multi-Target-Directed ligands in the search for novel lead candidates against trypanosoma and leishmania. J. Med. Chem. 2009, 52, 7339-7359.

2. Pieretti, S.; Haanstra, J.R.; Mazet, M.; Perozzo, R.; Bergamini, C.; Prati, F.; Fato, R.; Lenaz, G.; Capranico, G.; Brun, R.; Bakker, B.M.; Michels, P.A.M.; Scapozza, L.; Bolognesi, M.L.; Cavalli, A. Naphthoquinone derivatives exert their antitrypanosomal activity via a multi-target mechanism. PLOS Negl. Trop. Dis. 2013, 7, e2012. 
3. Prati, F.; Bergamini, C.; Molina, M.T.; Falchi, F.; Cavalli, A.; Kaiser, M.; Brun, R.; Fato, R.; Bolognesi, M.L. 2-Phenoxy-1,4-naphthoquinones: From a multitarget antitrypanosomal to a potential antitumor profile. J. Med. Chem. 2015, 58, 6422-6434.

4. Bruno, S.; Uliassi, E.; Zaffagnini, M.; Prati, F.; Bergamini, C.; Amorati, R.; Paredi, G.; Margiotta, M.; Conti, P.; Costi, M.P.; Kaiser, M.; Cavalli, A.; Fato, R.; Bolognesi, M.L. Molecular basis for covalent inhibition of glyceraldehyde-3-phosphate dehydrogenase by a 2-phenoxy-1,4-naphthoquinone small molecule. Chem. Biol. Drug Des. 2017, doi:10.1111/cbdd.12941.

(C) 2017 by the authors. Licensee MDPI, Basel, Switzerland. This article is an open access article distributed under the terms and conditions of the Creative Commons Attribution (CC BY) license (http://creativecommons.org/licenses/by/4.0/). 